\title{
Effects of progressive muscular relaxation and stretching exercises combination on blood pressure among farmers in rural areas of Indonesia: a randomized study ${ }^{\dagger}$
}

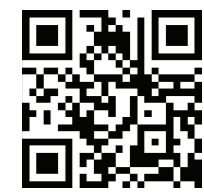

Original article

Tantut Susantoa,*, Retno Purwandarib, Emi Wuri Wuryaningsih ${ }^{c}$, Hirohito Watanabe ${ }^{\mathrm{d}}$, Kana Kazawa ${ }^{d}$, Michiko Moriyamad

${ }^{a}$ Community, Family, and Geriatric Nursing Department, Faculty of Nursing, Universitas Jember, Jawa Timur 68121, Indonesia ${ }^{b}$ Basic Sciences Nursing and Management Nursing Department, Faculty of Nursing, Universitas Jember, Jawa Timur 68121, Indonesia

'Psychiatric Nursing Department, Faculty of Nursing, Universitas Jember, Jawa Timur 68121, Indonesia

${ }^{\circledR}$ Graduate School of Biomedical and Health Sciences, Hiroshima University, Hiroshima 734-8553, Japan

Received: 14 February 2021; Accepted: 26 March 2021; Published: 20 December 2021

Abstract: Objective: Maintaining blood pressure (BP) could improve the quality of life among farmers in agricultural health. The study aims to evaluate the effects of progressive muscular relaxation and stretching exercises (SEs) for BP in farmer subjects in rural areas. Methods: A randomized controlled design was applied for this study. We performed a method, which is the combination of progressive muscle relaxation (PMR) and SEs for participants (30 in the control group and 60 in the intervention group). The intervention group self-practiced PMR and SEs through a video that providing instructions for $15 \mathrm{~min}$. PMR practiced before going to sleeping in the night, and SEs practiced before going to farms in the morning per day for 3-months. Wilcoxon signed-rank test was performed to measure the difference between systolic blood pressure (SBP) and diastolic blood pressure (DBP) as one pre- and post-test comparison of baseline and 3 months data in control and intervention groups.

Results: There were no significant differences between SBP and DBP pre- and post-test in control group $(P>0.050)$. Meanwhile, there were significant differences in reducing SBP $(M=126.67 ; \mathrm{SD}=18.07 ; 95 \% \mathrm{Cl}=120-147.5 \mathrm{mmHg})$ and DBP $(M=80.67 ; \mathrm{SD}=6.91$; $95 \% \mathrm{Cl}=80-90 \mathrm{mmHg})$ pre- and post-test combination of PMR and SEs in intervention group $(P<0.001)$. After 3-months of followup data, number type SBP and DBP still remained at the same levels of baseline and 3-month data in control group. While, there was an increased number of normal and prehypertension for SBP and DBP (10\% vs. $10 \%$ and $20 \%$ vs. $31.6 \%$ ) and reduced of hypertension stage I for SBP and DBP (30\% vs. $41.6 \%)$.

Conclusions: This pilot study demonstrated effectively to reduce SBP and DBP among farmers using the combination of PMR and SEs in the agricultural health setting.

Keywords: progressive muscular relaxation $\bullet$ stretching exercises $\bullet$ blood pressure $\bullet$ farmer $\bullet$ agricultural

(c) Shanxi Medical Periodical Press.

\section{Introduction}

The prevalence of hypertension in Indonesia is $26.5 \%{ }^{1}$ While the prevalence of hypertension systolic and hypertension diastolic among farmers is $45.2 \%$ and $35.8 \%$ respectively, both are correlated to worked overload. ${ }^{2}$ Provision of screening programs, health education programs, including dietary programs, and physical and

† This project was supported by the Ministry of Research, Technology, and Higher Education (KEMENRISTEK-DIKTI) for Hibah Bersaing Grant 2015-2016.

How to cite this article: Susanto T, Purwandari R, Wuryaningsih EW, Watanabe H, Kazawa K, Moriyamad M. Effects of progressive muscular relaxation and stretching exercises combination on blood pressure among farmers in rural areas of Indonesia: a randomized study. Front Nurs. 2021;4:365-374. 
exercise programs prevented and reduced health problems among farmers in the agricultural sector. ${ }^{3}$ Stretching exercise (SE) and progressive muscle relaxation (PMR) are effective interventions for maintaining health status, in particular, blood pressure (BP). ${ }^{4-6}$ Therefore, the PMR and SE are used as alternative program therapy to maintain BP among agricultural farmers.

As one of the behavioral techniques, PMR is used to reduce stress and anxiety 7,8 by focusing on movements to contract and relax muscles for controlling pain ${ }^{9}$ and improving mental state. ${ }^{6}$ Practically, PMR is used to reduce stress on various physical and mental problems. This technique was developed by Jacobson in $1934^{10}$ and later adapted by Berstein and Borkovec in 2000. ${ }^{11}$ The working mechanism of the PMR technique is to focus on the difference between feelings of anxiety and stress and relaxation. ${ }^{7-11}$ Controlling of feelings causes relaxation and reduces self-pressure, ${ }^{12}$ thus controls the hemodynamic of BP. Therefore, PMR is very safe and easy for behavioral intervention and this is highly recommended, because it does not require special expertise of techniques. ${ }^{12}$

Although the SE is a form of exercise for maintaining muscle fitness and elasticity, ${ }^{13}$ the mechanism of action of the SE will increase muscle flexibility and maintain blood circulation in the blood vessels smoothly by maintaining blood vessel elasticity. ${ }^{14}$ Hemodynamic conditions, heart rate, and BP can be controlled optimally through regular SEs. ${ }^{15}$

Lifestyles, characteristics of working conditions, and the environment are associated with farmers' health problem $^{3}$ and these factors influenced the quality of life among farmers in agricultural health, ${ }^{16}$ especially in maintaining their BP. Previous studies mentioned that the PMR was effective in decreasing systolic blood pressure (SBP) and diastolic blood pressure (DBP), ${ }^{17}$ whereas the SE reduced peripheral and central BP. ${ }^{5}$ Using a combination of PMR and SE is an important strategic intervention for maintaining BP among farmers.

In addition, rural areas of Indonesia are an administrative area at the village level that does not meet certain requirements in terms of population density, percentage of agricultural households, and a number of urban, formal education, and public health facilities. ${ }^{18}$ The characteristics of urban areas of Indonesia are marked by the very large role of primary groups, whereas geographical factors determine the formation of community groups, relationships are more intimate and durable, social structures are homogeneous, social mobility is low, families are more dictated by their functions as economic units, and the proportion of children is quite large in population structure. ${ }^{19}$ Meanwhile, farmers in Indonesia are individuals or groups of farmers who work in the agricultural sector by carrying out various cultivating activities in agricultural fields in rural areas and they spent the most time of day-to-day activities in the fields to produce products from agriculture. ${ }^{20}$ Farmers are at-risk for health problems because of their lifestyle and hazards in agricultural areas, ${ }^{3}$ including hypertension. ${ }^{21}$ Therefore, BP should be maintained for improving the healthy life among farmers.

Furthermore, controlling BP among farmers is useful for improving their health status. Maintaining BP could the improve quality of life among farmers for supporting their health and safety in agricultural health. Therefore, this study aims to evaluate the effects of PMR and SE on the BP of farmer subjects in rural areas of Indonesia.

\section{Methods}

\subsection{Design and participants}

The randomized controlled trial was conducted involving subjects of farmers from April 2016 to January 2017 using CONSORT guidelines. Researchers identified 155 subjects in four public health centers (PHC) from the rural areas of Jember, East Java province in Indonesia. In this study, we selected farmers as subjects because farmers are at higher risk to health problems compared with others in the community, due to lifestyles, characteristics of working conditions, and the environment associated with farmers health problem ${ }^{3}$ that have an influence on the quality of life among farmers in agricultural health, ${ }^{16}$ especially in maintaining their BP.

The inclusion criteria were: farmers age 18-50 years old, because in Indonesia government this range of age is defined as an adult; with normal and/or hypertension stage I (SBP: 140-159 mmHg and DPB: $90-99 \mathrm{mmHg}$ ) are regarded as the saving patients standard from the ethical committee for intervention study which is also a standard from The Eight Joint National Committee on Prevention, Detection, and Treatment of High Blood Pressure (JNC VIII), ${ }^{22}$ working as farmers and having a commitment to attending study protocol for 3 months. The exclusion criteria were: farmers with experienced stroke as they are not eligible for SE, ${ }^{5}$ hypertension stage II and over, taking medication, and hospitalized.

\subsection{Outcomes}

The main outcomes in this study were SBP and DBP which were measured using a standard protocol employing a stethoscope and sphygmomanometer after stabilizing the subjects for $>10 \mathrm{~min}$. Measurements of SBP and DBP $(\mathrm{mmHg})$ were categorized based on JNC VIII to determine hypertension for participants aged $>18$ years. $^{22}$ 
The researchers also observed the length of working per day, time of rest during working, and hours slept per day among the farmers. These indicators were measured, and caused influences on BP among farmers based on previous studies for comaprison. ${ }^{2,3}$

\subsection{Recruitment and randomization}

First public health nurses (PHNs) visited the areas and announced their program to the farmers and requested for participation. The recruitment was opened for 6 months (from April to September 2016). The farmers, who came to $\mathrm{PHC}$, were explained, obtained informed consent, and randomized by computer-generated number. As this was a pilot study, researchers did not set sample size calculation and running of the program was started from October to December 2016. The allocation sequence was concealed from the researchers and farmers. The initial names of farmers from $\mathrm{PHC}$ were randomized by computer-generated numbers. Then, the $\mathrm{PHN}$ from $\mathrm{PHC}$ obtained informed consent and then were allocated to control or intervention groups.

\subsection{Data collection}

At baseline, sociodemographic data, including age, gender, education level, smoking, hours of work and rest in working, and hours of sleeping per day, were obtained using a self-administered questionnaire by local PHNs registered farmers in PHCs. Measurement of SBP and DBP were conducted in PHC, while measuring SBP and DBP, the participants are made to sit in chairs and allowed 10 min relax, then PHNs measured $\mathrm{BP}$ at least 2 times. If the results of the second measurement differ by $10 \mathrm{mmHg}$ on comparing to the first measurement, then the third measurement was carried out. From the two measurement data, the data having the smallest difference with the last measurement was calculated. ${ }^{23}$

\subsection{Intervention}

The intervention group self-practiced PMR and SE through a video of instructions for 15 min developed by the researchers. Fifteen minutes was applied to study intervention consistently regarding that 16 major muscle groups and 1 set of 18 active and 20 passive stretches were needed $15 \mathrm{~min}$ to finish the practices. PMR and SE used a standard protocol from previous studies. PMR is performed by sitting comfortably in a half-lying position according to the procedure recommended by Bernstein and Borkovec for tension-release in 16 major muscle groups, ${ }^{11,24}$ which are shown in Figure 1.
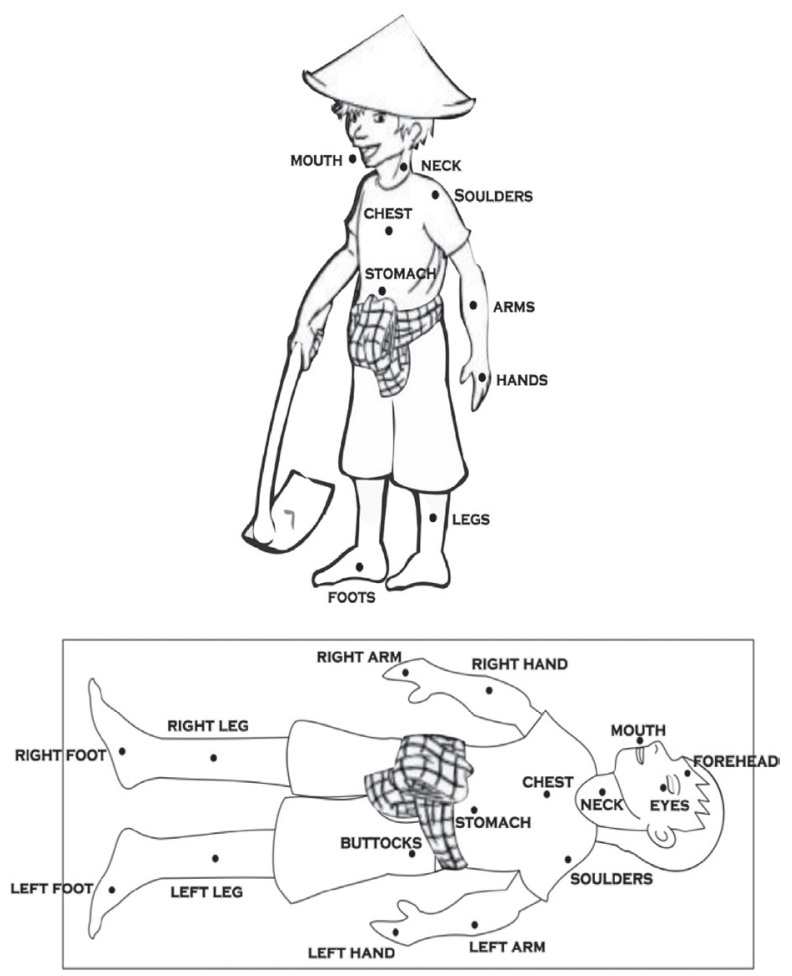

Figure 1. PMR from Bernstein and Borkovec for tension release in 16 major muscle groups. PMR, progressive muscle relaxation.

SE is performed in 1 set of 18 active and 20 passive stretches with at least 2 of them for the major muscle groups (pectoralis major and minor, latissimus dorsi, bicep brachii, triceps, deltoid, trapezius, illiopsas, gluteus, quadriceps, hamstring, leg adductors, and gastrocnemius) in the standing, sitting, and lying positions. ${ }^{5}$ In this study, the participants practiced PMR before sleeping in the night and SE before going to farms in the morning every day for 3 months. Previous studies mentioned that PMR was effective for treating mild hypertension for 11 sessions in 6 weeks after the intervention, ${ }^{25}$ and SE has reduced BP for 8 weeks training of stretching. ${ }^{5}$ Therefore, researchers decided to use a combination of PMR and SE in this study for 3 months in the intervention group.

The control group received education about health and safety in the farmer areas. In the control group, farmers applied healthy behaviors based on the results of the health education from which they had previously attended. Farmers in the control group are armed with the results of health education, trying to control healthy life in the occupational health and safety order in the agricultural environment.

For both groups, health education was provided initially before the program started, which included how to 
manage a healthy lifestyle during the time when working as farmers, dietary, exercises, rest and sleeping, and BP problem of farmer workers. The health education was performed in one session for 60 min for the first meeting of screening the participants and then all of the participants received a manual book of healthy lifestyle in an agricultural setting area.

Both groups maintained their BP. If the BP of a farmer was increased to hypertension stage II and over, the Medical Doctor in PHC prescribed antihypertensive medicine. Then, the farmer was excluded from this study. During the program, among the farmers, 6 farmers in control groups were referred to hospital due to hypertension stage II and over and they started antihypertensive medicine (Figure 2).

Data were measured at when registered and at $3^{\text {rd }}$ month when the program ended. For BP data, researchers rounded off the data based on $\mathrm{PHNs}$ measuring in the range $1-4 \mathrm{mmHg}, 5 \mathrm{mmHg}$, and $6-10 \mathrm{mmHg}$. For example, BP $120 \mathrm{mmHg}$ (rounded off as data 120$124 \mathrm{mmHg}$ ), $125 \mathrm{mmHg}$, and $130 \mathrm{mmHg}$ (rounded off as data $126-130 \mathrm{mmHg}$ ).

\subsection{Statistical analysis}

SPSS version 22 was used for the analysis. The statistically significant level was set at $P<0.050$. Man Whitney$U$ test and Chi-square test were used to measure the differences at baseline of participants and BP between control and intervention groups.

Because of the higher drop in participants of the control group, it made significant differences between two groups on outcomes at baseline (SBP, $P=0.177$; and DBP, $P=0.044$ ), Wilcoxon signed-rank test was performed to measure the difference in SBP and DBP as one pre- and post-test comparison between baseline and 3 months data in control and intervention groups. Then, the Chi-square test was used to measure the comparison of number of type BP baseline and 3 months data in control and intervention groups.

\section{Results}

Among 155 participants assessed for eligibility in this study, 25 participants were excluded from the study (not

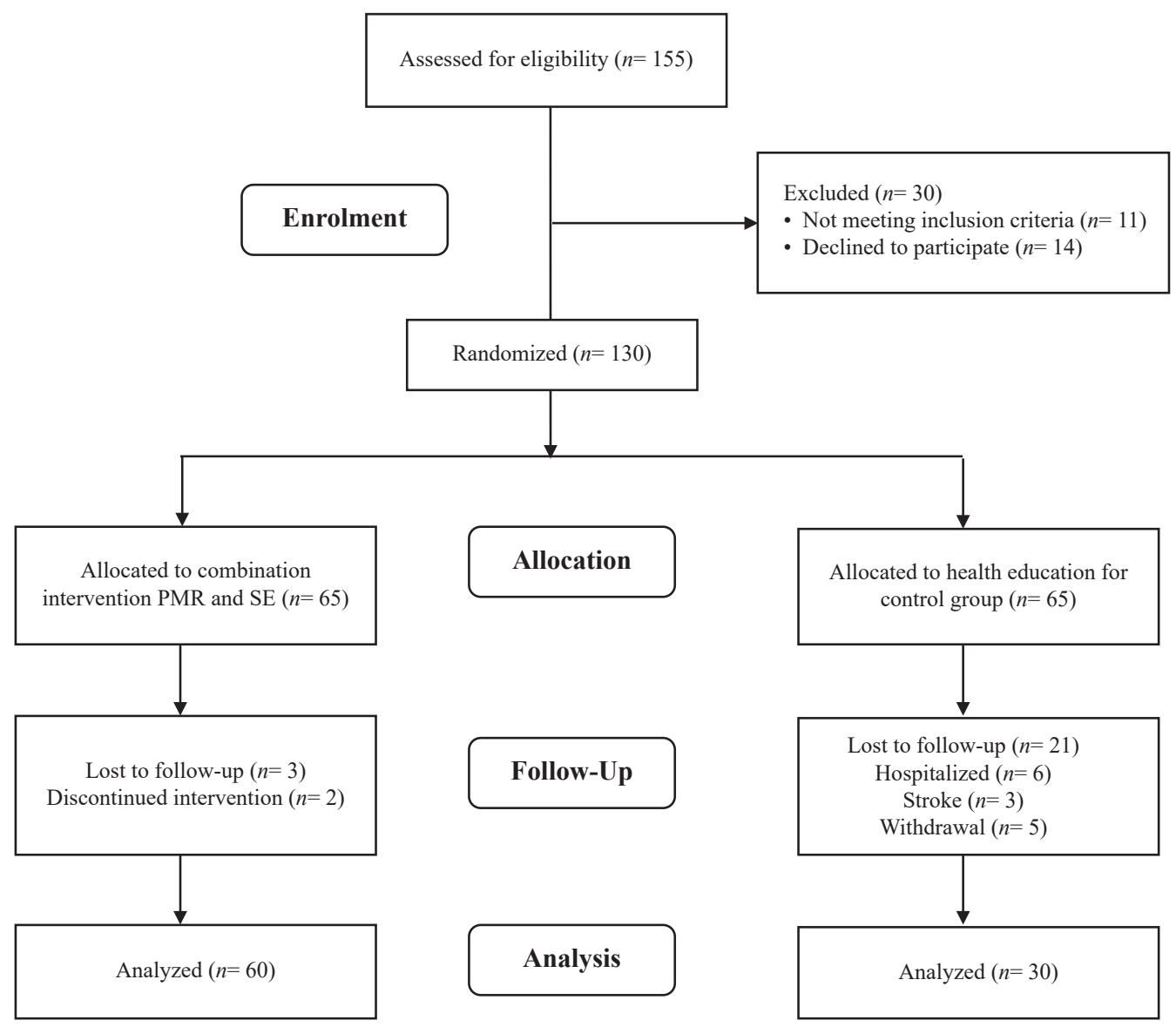

Figure 2. CONSORT Flow Diagram for enrollment, allocation, and follow-up study participant. PMR, progressive muscle relaxation; SE, stretching exercise. 
meeting inclusion criteria $=11$ and declined to participate $=14)$. Then, a total of 130 participants participated in this study. The 130 participants were allocated randomly to two groups (intervention group $=65$ and control group $=65$ ).

During the intervention, 5 participants dropped from the intervention group (lost to follow-up $=3$ and discontinued intervention $=2$ ). In contrast, 35 participants dropped from control group (lost to follow-up $=21$, hospitalized $=6$, experienced stroke $=3$, and withdrew from the study =5). At the end of the study, there was an unequal sample distribution leading to losses. Approximately, $53.8 \%$ of participants in the control group dropped in this study, because participants felt very bored due to the monotonous behavior of the results of health education. Though they felt that they had many complaints about BP, but did not have enough access to the PHCs (Figure 2).

Table 1 shows from baseline data $(n=130)$, there were no statistically significant differences in the baseline characteristics of participant, SBP, and DBP in control and intervention groups $(P>0.050)$.
Table 2 shows that there were no significant differences in SBP and DBP pre- and post-test in the control group $(P>0.05)$. However, there were significant differences reducing SBP $(130 \mathrm{mmHg}$ vs. $90 \mathrm{mmHg}$; $Z=-5.381)$ and DPB (90 $\mathrm{mmHg}$ vs. $80 \mathrm{mmHg}$; $Z=-5.038)$ pre- and post-test combination of PMR and SE in the intervention group $(P<0.001)$.

Table 3 shows the comparison of number of type BP baseline and 3 months data in the control group $(n=30)$. There were significant differences baseline and 3 month data in control group for $\operatorname{SBP}\left(\chi^{2}=60.0 ; P<0.001\right)$ and DBP $\left(\chi^{2}=50.0 ; P<0.001\right)$. The number of type SBP remained baseline and 3 month data. For type DBP, there were remained the number normal $\mathrm{BP}$, although there were increased number of pre hypertension (6.7\%) and reduced number of hypertension stage I (6.7\%) from baseline and 3 month data.

Meanwhile, in intervention group $(n=60)$, the comparison of number of type BP baseline and 3 months data shows that there were significant differences baseline and 3 month data in intervention group for SBP $\left(\chi^{2}=54.13 ; P<0.001\right)$ and $\operatorname{DBP}\left(\chi^{2}=23.92 ; P=0.001\right)$

\begin{tabular}{|c|c|c|c|c|c|}
\hline Variable & Total & Control $(n=65)$ & Intervention $(n=65)$ & $z / \chi^{2}$ & $P$-value \\
\hline \multicolumn{6}{|l|}{ Age (year) } \\
\hline $\mathrm{Md}\left(\mathrm{P}_{25}-\mathrm{P}_{75}\right)$ & $45(40.7-50.0)$ & $46(39.5-56.0)$ & $45(41.0-48.0)$ & -1.149 & 0.250 \\
\hline \multicolumn{6}{|l|}{ Gender $n(\%)$} \\
\hline Male & $107(82.3)$ & $49(75.4)$ & $58(89.2)$ & 3.381 & 0.066 \\
\hline Female & $23(17.7)$ & $16(24.6)$ & $7(10.8)$ & & \\
\hline \multicolumn{6}{|l|}{ Education level $n$ (\%) } \\
\hline Not attending & $17(13.1)$ & $11(16.9)$ & $6(9.2)$ & 1.787 & 0.618 \\
\hline Elementary school & $93(71.5)$ & $45(69.2)$ & $48(73.8)$ & & \\
\hline Junior high school & $13(10.0)$ & $6(9.2)$ & $7(10.8)$ & & \\
\hline Senior high school & $7(5.4)$ & $3(4.6)$ & $4(6.2)$ & & \\
\hline \multicolumn{6}{|l|}{ Smoking $n(\%)$} \\
\hline No & $89(68.5)$ & $39(60.0)$ & 50 (76.9) & 3.563 & 0.059 \\
\hline Yes & $41(31.5)$ & $26(40.0)$ & $15(23.1)$ & & \\
\hline \multicolumn{6}{|c|}{ Length of working per day (h) } \\
\hline $\mathrm{Md}\left(\mathrm{P}_{25}-\mathrm{P}_{75}\right)$ & $6.0(5.0-7.0)$ & $6.0(5.0-8.0)$ & $6.0(4.0-7.0)$ & -1.304 & 0.192 \\
\hline \multicolumn{6}{|c|}{ Length of rest in working (h) } \\
\hline $\mathrm{Md}\left(\mathrm{P}_{25}-\mathrm{P}_{75}\right)$ & $2.0(2.0-3.0)$ & $2.0(2.0-3.5)$ & $2.0(1.0-3.0)$ & -1.767 & 0.077 \\
\hline \multicolumn{6}{|c|}{ Length of sleeping per day (h) } \\
\hline $\mathrm{Md}\left(\mathrm{P}_{25}-\mathrm{P}_{75}\right)$ & $6.0(5.0-7.0)$ & $6.0(5.0-8.0)$ & $6.0(5.0-7.0)$ & -1.459 & 0.145 \\
\hline \multicolumn{6}{|l|}{$\operatorname{SBP}(m m H g)$} \\
\hline $\mathrm{Md}\left(\mathrm{P}_{25}-\mathrm{P}_{75}\right)$ & $130(120-140)$ & $130(120.0-142.5)$ & $130(120-140)$ & -0.939 & 0.348 \\
\hline \multicolumn{6}{|l|}{$D B P(m m H g)$} \\
\hline $\mathrm{Md}\left(\mathrm{P}_{25}-\mathrm{P}_{75}\right)$ & $80(80-90)$ & $80(80-90)$ & $90(80-90)$ & -1.914 & 0.056 \\
\hline
\end{tabular}

Note: $Z$ was determined using Mann Whitney- $U$ test; $\chi^{2}$ was determined using Chi-square test. $\mathrm{BP}$, blood pressure; DBP, diastolic blood pressure; SBP, systolic blood pressure.

Table 1. Baseline characteristics of participant and BP $(n=130)$. 


\begin{tabular}{|c|c|c|c|c|c|c|}
\hline \multirow{2}{*}{ Variable } & \multicolumn{3}{|c|}{ Control $(n=30)$} & \multicolumn{3}{|c|}{ Intervention $(n=60)$} \\
\hline & $\mathrm{Md}\left(\mathrm{P}_{25}-\mathrm{P}_{75}\right)$ & Z & $P$-value & $\mathrm{Md}\left(\mathrm{P}_{25}-\mathrm{P}_{75}\right)$ & Z & $P$-value \\
\hline \multicolumn{7}{|c|}{$\mathrm{SBP}(\mathrm{mmHg})$} \\
\hline Pre & $120.0(110.0-150.0)$ & -1.732 & 0.083 & $130.0(120.0-147.5)$ & -5.381 & $<0.001^{*}$ \\
\hline Post & $120.0(110.0-150.0)$ & & & $120.0(110.0-130.0)$ & & \\
\hline \multicolumn{7}{|c|}{$D B P(m m H g)$} \\
\hline Pre & $80.0(80.0-90.0)$ & -1.342 & 0.180 & $90.0(80.0-90.0)$ & -5.038 & $<0.001^{*}$ \\
\hline Post & $80.0(80.0-85.0)$ & & & $80.0(76.25-83.75)$ & & \\
\hline
\end{tabular}

Note: *Determined using Wilcoxon Signed Ranks Test.DBP, diastolic blood pressure; SBP, systolic blood pressure.

Table 2. Comparison of SBP and DBP baseline and 3 months data in control and intervention groups $(n=90)$.

\begin{tabular}{|c|c|c|c|c|c|c|c|c|}
\hline \multirow[b]{2}{*}{$\mathrm{BP}$} & \multicolumn{4}{|c|}{ SBP } & \multicolumn{4}{|c|}{ DBP } \\
\hline & Baseline $(n)$ & 3 months $(n)$ & Changing (\%) & $\chi^{2}(P$-value $)$ & Baseline $(n)$ & 3 months $(n)$ & Changing (\%) & $\begin{array}{c}\chi^{2} \\
\text { (P-value })\end{array}$ \\
\hline Normal & 10 & 10 & 0 & 60.0 & 6 & 6 & 0 & 50.0 \\
\hline Pre hypertension & 10 & 10 & 0 & $(<0.001)$ & 16 & 18 & +6.7 & $(<0.001)$ \\
\hline Hypertension stage I & 10 & 10 & 0 & & 8 & 6 & -6.7 & \\
\hline Hypertension stage II & 0 & 0 & 0 & & 0 & 0 & 0 & \\
\hline
\end{tabular}

Note: JNC VII (National Heart, Lung, 2003); Normal (SBP < 120 mmHg; DBP < 80 mmHg), Pre hypertension (DBP = 120-139 mmHg), Hypertension stage I (SBP = 140-159 mmHg), and Hypertension stage II (SBP > $160 \mathrm{mmHg}$; DBP > $100 \mathrm{mmHg})$.

Table 3. The comparison of number of type BP baseline and 3 months data in the control group $(n=30)$.

\begin{tabular}{|c|c|c|c|c|c|c|c|c|}
\hline \multirow[b]{2}{*}{ Baseline } & \multicolumn{4}{|c|}{ SBP } & \multicolumn{4}{|c|}{ DBP } \\
\hline & Baseline $(n)$ & 3 months $(n)$ & Changing (\%) & $\chi^{2}(P$-value $)$ & Baseline $(n)$ & 3 months $(n)$ & Changing (\%) & $\begin{array}{c}\chi^{2} \\
(P \text {-value })\end{array}$ \\
\hline Normal & 10 & 16 & +10.0 & 43.2 & 9 & 15 & +10.0 & 34.7 \\
\hline Pre hypertension & 24 & 36 & +20.0 & $(<0.001)$ & 19 & 38 & +31.6 & $(<0.001)$ \\
\hline $\begin{array}{l}\text { Hypertension } \\
\text { stage I }\end{array}$ & 26 & 8 & -30.0 & & 32 & 7 & -41.6 & \\
\hline $\begin{array}{l}\text { Hypertension } \\
\text { stage II }\end{array}$ & 0 & 0 & 0 & & 0 & 0 & 0 & \\
\hline
\end{tabular}

Note: JNC VII (National Heart, Lung, 2003); Normal (SBP < 120 mmHg; DBP < 80 mmHg), Pre hypertension (DBP = 120-139 mmHg), Hypertension stage I (SBP = 140-159 mmHg), and Hypertension stage II (SBP > $160 \mathrm{mmHg}$; DBP > $100 \mathrm{mmHg})$.BP, blood pressure; DBP, diastolic blood pressure; JNC VII, The Seven Report of the Joint National Committee on Prevention, Detection, and Treatment of High Blood Pressure; SBP, systolic blood pressure. BP, blood pressure; DBP, diastolic blood pressure; JNC VII, The Seven Report of the Joint National Committee on Prevention, Detection, and Treatment of High Blood Pressure; SBP, systolic blood pressure.

Table 4. The comparison of number of type BP baseline and 3 months data in the intervention group $(n=60)$

as shown in Table 4. There was increased number of normal and pre hypertension for SBP and DBP (10\% vs. $10 \%$; and $20 \%$ vs. $31.6 \%$ ), and reduced hypertension stage I for SBP and DBP (30\% vs. $41.6 \%)$.

Table 5 shows the distribution of participants based on BP categories among dropout of participants in the control group ( $n=35)$ and intervention group $(n=5)$. We observed the parameters of the majority of the control group: SBP with normal $=11.4 \%$, pre hypertension $=51.4 \%$, hypertension stage $\mathrm{I}=37.1 \%$; and all of
DBP with normal; whereas the intervention group (SBP with pre hypertension $=80 \%$ and hypertension stage $\mathrm{I}=20 \%$; and all of DBP with normal).

\section{Discussion}

This pilot study demonstrated effective improvement of $\mathrm{BP}$ among farmers using the combination of PMR and $\mathrm{SE}$ in agricultural health settings in Indonesia. After 3 months of follow-up, it is observed that the combination 


\begin{tabular}{|c|c|c|c|c|}
\hline \multirow[t]{2}{*}{$\mathrm{BP}$} & \multicolumn{2}{|c|}{ Control $(n=35)$} & \multicolumn{2}{|c|}{ Intervention $(n=5)$} \\
\hline & Systolic, $n(\%)$ & Diastolic, $n$ (\%) & Systolic, $n(\%)$ & Diastolic, $n(\%)$ \\
\hline Normal & $4(11.4)$ & $35(100.0)$ & 0 & $5(100.0)$ \\
\hline Pre hypertension & $18(51.4)$ & 0 & $4(80.0)$ & 0 \\
\hline Hypertension stage I & $13(37.1)$ & 0 & $1(20.0)$ & 0 \\
\hline Hypertension stage II & 0 & 0 & 0 & 0 \\
\hline
\end{tabular}

Note: JNC VII (National Heart, Lung, 2003); Normal (SBP < 120 mmHg; DBP < 80 mmHg), Pre hypertension (DBP = 120-139 mmHg), Hypertension stage I (SBP = 140-159 mmHg), and Hypertension stage II (SBP > $160 \mathrm{mmHg}$; DBP > $100 \mathrm{mmHg})$.

BP, blood pressure; DBP, diastolic blood pressure; JNC VII, The Seven Report of the Joint National Committee on Prevention, Detection, and Treatment of High Blood Pressure; SBP, systolic blood pressure.

Table 5. Distribution of number BP values among drop out of participant in control and intervention group.

of PMR and SE significantly reduced SBP and DBP values in the intervention group compared with the control group. Therefore, the combination of PMR and SE is effective in reducing the SBP and DBP among farmers. The magnitude of reduction in BP was similar to those reported regarding the $\mathrm{SE}$ decreasing $\mathrm{BP}^{5,26}$ and $\mathrm{PMR}$ reducing BP. ${ }^{17}$ These effects were clinically and statistically significant, as discussed below.

This study found that in the intervention group SBP and DBP were reduced among farmers after practicing the combination of PMR and SE. This is likely because, in the intervention group, the farmers learned and practiced SE movements as routine activities in the morning before going to work in the fields. After practicing SE optimally, it is possible for the body to relax more and the muscles may be ready for doing the main work, ${ }^{27}$ so that the cardio-respiration of the body will get maintained and the daily pattern of BP is controlled. ${ }^{26,28}$ Therefore, adequate training is needed for $15 \mathrm{~min}$ for the farmers before doing the core work in the agricultural fields.

SBP and DBP were reduced in the intervention group after practicing PMR for 3 months. This may be explained that PMR in 16 muscle groups, allows farmers to relax their muscles that have been used after working in the agricultural fields. Muscle relaxation provides an opportunity for muscles to be able to restore the situation by replacing damaged cells with new cells. ${ }^{27}$ Thus, the process of using muscles is balanced with the recovery process of cell and muscle tissue, so that $\mathrm{BP}$ is controlled. ${ }^{25,29}$ Therefore, PMR is needed for the farmer for $15 \mathrm{~min}$ before the farmers start to sleep, and getting adequate rest and adequate sleep will be able to support the maintenance of controlled BP.

This study identified that almost more than a half of participants in the control group dropped out in this study which reflected that no comparable number of participants left in the control group for the analysis. This indicated differential dropout that caused the results to be biased. ${ }^{30}$ Therefore, researchers analyzed each one group pre- and post-test. The reasons for participant dropout in this study was the BP measurement indicating pre hypertension and hypertension stage I that caused participants in the control group to be hospitalized and experienced stroke. The 3 months of study in the control group reflected un-compliance with lost to follow-up and withdrawal. Non-compliance is generally a problem that arises in clinical intervention studies, which requires a long time period and is not reliable if all participants follow the clinical intervention. ${ }^{31}$ Therefore, researchers analyzed type BP baseline and 3 months data in control and intervention groups, separately. The main outcome in this study was $\mathrm{BP}$, which was controlled in the subjects, here farmers, through a home visit to maintain PMR and SE program. If farmers were taking medication, researchers eliminated them from this study. Researchers were maintaining farmers so that they strictly follow the instruction of the study, although some participants-researchers were dropped due to problems in the part of the results. Researchers also used local PHNs as a third-person approach to monitor the adherence of PMR and SE practices by farmers who had training at the first-time meeting in this study.

Researchers knew factors that affected BP, including salt consumption, smoking, and medication adherence, ${ }^{32}$ family social support, depression, anxiety, and self-efficacy, ${ }^{33}$ and physical activity. ${ }^{34}$ However, in this study, researchers focused on SE as management for physical activity and PMR to reduce depression and anxiety among farmers. Therefore, researchers could maintain their BP. Then, in the study, researchers measured the main outcomes of the BP and researchers did not take the others tests and controlled the other variables. This is the community study and no other lab test could be conducted in rural areas of Indonesia which confirmed the results of previous studies that access to medicines facilitation ${ }^{35}$ and social condition ${ }^{36}$ 
are influencing factors in managing hypertension in rural areas of Indonesia.

The study found that the number of type BP of SBP and DPB were significantly different between baseline and 3 month data in the control and the intervention group. In particular, there was a decrease in the number of participants who experienced hypertension stage $I$ in the intervention group. An overview of the results showed that SBP and DBP in the control group remained as such even after 3 months of follow-up. This requires an optimal health education in the farmer group, and it should be noted that regular BP checks at the PHCs will be able to measure the actual state of $\mathrm{BP}^{37}$ leading to early identification of health problems in farmers. The health screening program can be done by integrating the health care system of farmers to rural areas to facilitate access to quality health services.

\subsection{Strength of the study}

The study report shows that the intervention and control groups were highly similar in key characteristics before the application of the intervention. The study obtained a high attrition sample which undermined the equivalence of the intervention and control groups. The study placed the sample members in the original group to which they were randomly assigned. It was observed that when the intervention group members who failed to participate in or complete the intervention, retaining in the intervention group is consistent as per guidelines. The test study used to measure the outcomes are ones whose ability to measure true outcomes is well-established.

Several biases were observed and led to a high attrition rate in the study which should not be taken for granted especially if it affects the validity of results. Continuous monitoring of the application of intervention is highly significant. The study reports that the intervention's effect on all the outcomes that the study measured is not just those for whom there is a positive effect. The study established a strong confidence that an intervention would be effective with the trials evaluated the intervention in the real-world community setting and conditions where it would normally be implemented. The trial addressed clearly focused issues especially the sample being studied, the intervention and comparator given, and the outcomes considered. More so, the assignment of patients to treatments was randomized. However, it was not indicated if the allocation sequence was not revealed to the researchers and farmers. All clinically important outcomes were considered with benefits worth the harms and effort.

\subsection{Implication for practice}

This study provides an innovation for PHNs practices in the rural setting of farmers suggesting that the combination of PMR and SE could be used for alternative intervention for maintaining BP among farmers in the setting of agricultural health. PHNs could use these combination therapies among self-care group of farmers in the community with monitoring and supervising of local PHCs. PHNs also could develop agricultural nursing services for screening BP and checking to continue farmers' BP to PHCs. Health education and health management system integrated with PMR and SE as a nursing intervention could be applied among farmers.

\section{Conclusions}

The combination of PMR and SE is effective in reducing BP among farmers. After 3 months follow-up of the data, the number of type SBP and DBP remained at baseline levels in the control group; while the number of SBP and DBP categories increased to normal and pre hypertension after 3 months of intervention. Therefore, a combination of PMR and SE could be implemented as an occupational health nursing program by $\mathrm{PHNs}$ in the farmer population. Furthermore, controlled compliance of participants in randomized controlled trails for clinical practice research should be done for reducing drop-out subjects in a community health setting research.

\section{Limitations}

The implementation of a combination of PMR and SE in this study has several limitations. The PMR and SE practice program urgently requires compliance by farmers in carrying out regular and continuous training to maintaining their BP, although the number of participants who dropped out is high in this study. Therefore, scheduled supervision is needed from PHNs to increase the independence of farmers in conducting PMR and SE.

The method of measuring BP was performed by rounding off data and the results did not describe the true state of BP values. Measurements should be taken based on PHNs related to the operational standards of BP measurement procedures in PHCs. Then, for further research, matching of the subject in the control and intervention groups for randomized controlled trial study should be done and so a large number of samples are needed in the population of farmers with hypertension. Thus, the effectiveness of therapy can be assessed more objectively and can become a standard of therapy in the community.

Researchers used RCTs design. Therefore, samples are grouped randomly equal with the only 
difference being the intervention so to decide if the results are trustworthy. However, in this study, samples were later become unequal due to losses. Despite lost to follow-up, the study explained the losses with appropriate management using and analyzing 1-group preand post-test. Then, researchers conducted random assignment in groups at the appropriate level, however, unequal at the end. It is assumed that the study had an adequate sample size which was large enough to detect meaningful effects of the intervention as the study found that the intervention produced statistically significant effects.

\section{References}

1. Badan Penelitian dan Pengembangan Kesehatan. Riset Kesehatan Dasar (RISKESDAS) 2013. Laporan Nasional 2013 (2013) (in Indonesian).

2. Susanto T, Purwandari R, Wuri Wuryaningsih E. Model Kesehatan Keselamatan Kerja Berbasis agricultural nursing: Studi Analisis Masalah Kesehatan Petani (Occupational health nursing modelbased agricultural nursing: a study analyzes of farmers health problem). J Ners. 2016;11:45-50 (in Indonesian).

3. Susanto T, Purwandari R, Wuri E. Prevalence and associated factors of health problems among Indonesian farmers. Chin Nurs Res. 2017;4:31-37.

4. Cottier C, Shapiro K, Julius S. Treatment of mild hypertension with progressive muscle relaxation. Predictive value of indexes of sympathetic tone. Arch Intern Med. 1984;144:1954-1958.

5. Wong A, Figueroa A. Eight weeks of stretching training reduces aortic wave reflection magnitude and blood pressure in obese postmenopausal women. J Hum Hypertens. 2014;28:246-250.

6. Kapogiannis A, Tsoli S, Chrousos G. Investigating the effects of the progressive muscle relaxation-guided imagery combination on patients with cancer receiving chemotherapy treatment: a systematic review of randomized controlled trials. Explore 2018;14:137-143.

7. Gurav RS, Nahar SK. Effect of progressive muscle relaxation on anxiety in geriatric population. Int $J$ Sci Res. 2019;7:76-78.

8. Sulastini S, Mediani HS, Fitria N, Nugraha BA. Effect of progressive muscle relaxation on anxiety in congestive heart failure patients. J Keperawatan Soedirman. 2019;14.

9. Jaworska L, HawrylakA, Burzyński B, SzczepańskaGieracha J. Effect of progressive muscle relaxation on pain threshold and effectiveness of footballers' training. Hum Mov. 2015;16:225-228.

\section{Ethical approval}

The institutional ethics committee approved the study. This study was approved by the health department with No. 440/18123/414/2016 and the national and political unity agency with No. 072/904/314/2016. Informed consent was given to all participants during the selection into the research subjects.

\section{Conflicts of interest}

All contributing authors declare no conflicts of interest.

10. Parás-Bravo P, Alonso-Blanco C, Paz-Zulueta M, et al. Does Jacobson's relaxation technique reduce consumption of psychotropic and analgesic drugs in cancer patients? A multicenter pre-post intervention study. BMC Complement Altern Med. 2018;18:1-9.

11. Unger CA, Busse D, Yim IS. The effect of guided relaxation on cortisol and affect: stress reactivity as a moderator. J Health Psychol. 2017;22:29-38.

12. Limsanon T, Kalayasiri R. Preliminary effects of progressive muscle relaxation on cigarette craving and withdrawal symptoms in experienced smokers in acute cigarette abstinence: a randomized controlled trial. Behav Ther. 2015;46:166-176.

13. Page P. Clinical commentary current concepts in muscle stretching for exercise and rehabilitation. Int J Sports Phys Ther. 2012;7:109-119.

14. Lee E-O, Lee K-H, Kozyreva O. The effect of complex exercise rehabilitation program on body composition, blood pressure, blood sugar, and vessel elasticity in elderly women with obesity. J Exerc Rehabil. 2014;9:514-519.

15. de Melo Fiuza AGF, et al. Order effects of resistance and stretching exercises on heart rate variability and blood pressure in healthy adults. J Strength Cond Res. 2019;33:2684-2693.

16. Susanto T, Widayati N. Quality of life of elderly tobacco farmers in the perspective of agricultural nursing: a qualitative study. Work Older People. 2018;22:166-177.

17. Aalami M, Jafarnejad F, ModarresGharavi M. The effects of progressive muscular relaxation and breathing control technique on blood pressure during pregnancy. Iran $J$ Nurs Midwifery Res. 2016;21:331.

18. Badan Pusat Statistik. Peraturan Kepala Badan Pusat Statistik Nomor 37 Tahun 2010 Tentang Klasifikasi Perkotaan dan Perdesaan di Indonesia. 2010;2 (in Indonesian). 
19. Breckenkamp J, Patterson L, Scharlach M, Hellmeier W, Verma A. Definitions of urban areas feasible for examining urban health in the European Union. Eur J Public Health. 2017;27:19-24.

20. Desiana N, Aprianingsih A. Improving income through farmers' group empowerment strategy. Asian J Technol Manag. 2017;10:41-47.

21. Shin DS, Kim CJ, Choi YJ. Effects of an empowerment program for self-management among rural older adults with hypertension in South Korea. Aust J Rural Health. 2016;24:213-219.

22. James PA, Oparil S, Carter BL, et al. 2014 Evidence-based guideline for the management of high blood pressure in adults: report from the panel members appointed to the Eighth Joint National Committee (JNC 8). JAMA. 2014;311:507-520.

23. Ministry of Health Indonesia. Riset Kesehatan Dasar. Riset Kesehatan Dasar 2013 (Basic Health Research 2013), 2013.

24. Singh VP, Rao V, Prem V, Sahoo RC, Keshav PK. Comparison of the effectiveness of music and progressive muscle relaxation for anxiety in COPDA randomized controlled pilot study. Chron Respir Dis. 2009;6: 209-216.

25. Astuti NF, Rekawati E, Wati DNK. Decreased blood pressure among community dwelling older adults following progressive muscle relaxation and music therapy (RESIK). BMC Nurs. 2019;18:1-5.

26. da Silva Araujo G, Behm DG, Monteiro ER. Order effects of resistance and stretching exercises on heart rate variability and blood pressure in healthy adults. J Strength Cond Res. 2019;33:2684-2693.

27. Hotta K, Kamiya K, Shimizu R, et al. Stretching exercises enhance vascular endothelial function and improve peripheral circulation in patients with acute myocardial infarction. Int Heart J. 2013;54:59-63.

28. Inami T, Baba R, Nakagaki A, Shimizu T. Acute changes in peripheral vascular tonus and systemic circulation during static stretching. Res Sport Med. 2015;23:167-178.
29. Shinno H, Kurose S, Yamanaka Y, et al. Evaluation of a static stretching intervention on vascular endothelial function and arterial stiffness. Eur J Sport Sci. 2017;17:586-592.

30. Bell ML, Kenward MG, Fairclough DL, Horton NJ. Differential dropout and bias in randomised controlled trials: when it matters and when it may not. BMJ. 2013;346:e8668.

31. Armijo-Olivo S, Warren S, Magee D. Intention to treat analysis, compliance, drop-outs and how to deal with missing data in clinical research: a review. Phys Ther Rev. 2009;14:36-49.

32. Larki A, Tahmasebi R, Reisi M. Factors predicting self-care behaviors among low health literacy hypertensive patients based on health belief model in Bushehr district, South of Iran. Int J Hypertens. 2018;2018:1-7.

33. $\mathrm{Hu} \mathrm{HH}$, Li G, Arao T. The association of family social support, depression, anxiety and self-efficacy with specific hypertension self-care behaviours in Chinese local community. J Hum Hypertens. 2015;29:198-203.

34. Heydari H, Kamran A, Ahari SS, Biria M, Malepour A. Determinants of patient's adherence to hypertension medications: application of health belief model among rural patients. Ann Med Health Sci Res. 2014;4:922.

35. Rahmawati R, Bajorek BV. Access to medicines for hypertension: a survey in rural Yogyakarta province, Indonesia. Rural Remote Health. 2018; 18:4393.

36. Peltzer K, Pengpid S. The prevalence and social determinants of hypertension among adults in Indonesia: a cross-sectional population-based national survey. Int J Hypertens. 2018;2018:5610725.

37. Susanto $T$, Rasny $H$, Susumaningrum LA, Yunanto RA. Prevalence of hypertension and predictive factors of self-efficacy among elderly people with hypertension in institutional-based rehabilitation in Indonesia. Kontakt. 2019;21:14-21. 